\title{
Crinine-type alkaloids from Hippeastrum aulicum and H. calyptratum
}

Jean Paulo de Andrade ${ }^{\mathrm{a}, \mathrm{b}}$, Ying Guo ${ }^{\mathrm{a}}$, Mercè Font-Bardia ${ }^{\mathrm{c}, \mathrm{d}}$, Teresa Calvet ${ }^{\mathrm{c}}$, Jullie Dutilh ${ }^{\mathrm{e}}$, Francesc Viladomat ${ }^{\mathrm{a}}$, Carles Codina ${ }^{\mathrm{a}}$, Jerald J. Nair ${ }^{\mathrm{a}}$, Jose A. Silveira Zuanazzi ${ }^{\mathrm{f}}$, Jaume Bastida ${ }^{\mathrm{a}, \Uparrow}$

${ }^{\text {a }}$ Departament de Productes Naturals, Biologia Vegetal i Edafologia, Facultat de Farmàcia, Universitat de Barcelona, Av. Diagonal 643, 08028 Barcelona, Spain ${ }^{\mathrm{b}}$ Facultad de Farmacia, INIFAR and CIPRONA, Universidad de Costa Rica, 2060 San José, Costa Rica

${ }^{\mathrm{c}}$ Cristal $\cdot$ lografia, Mineralogia i Dipòsits Minerals, Universitat de Barcelona, Martí i Franquès s/n, 08028 Barcelona, Spain

${ }^{\mathrm{d}}$ Unitat de Difracció RX, Centre Cientific i Tecnològic (CCiTUB), Universitat de Barcelona, Sole Sabaris 1-3, 08028 Barcelona, Spain

e Departamento de Botânica, Universidade de Campinas, Cidade Universitária, Campinas 13083-970, Brazil

${ }^{\mathrm{f}}$ Faculdade de Farmácia, Universidade Federal do Rio Grande do Sul, 2752 Ipiranga Av., Porto Alegre 90610-000, Brazil

${ }^{\Uparrow}$ Corresponding author. Tel.: +34 934020268; fax: +34 934029043.

E-mail address: jaumebastida@ub.edu (J. Bastida). 
38

39

40

41

42

43

44

45

46

47

48

49
ABSTRACT

An ongoing search for alkaloids in the Amaryllidaceae species using GC-MS resulted in the identification of two crinine-type alkaloids, aulicine (1) and 3-O-methyl-epimacowine, (2) from the indigenous Brazilian species Hippeastrum aulicum and Hippeastrum calyptratum, respectively. In addition, two alkaloids, 11-oxohaemanthamine (3) and 7-methoxy-O-methyllycorenine (4) were both isolated from H. aulicum. Furthermore, we provide here complete NMR spectroscopic data for the homolycorine analogues nerinine (5) and albomaculine (6). The absolute stereochemistry of the 5,10bethano bridge in the crinine variants was determined by circular dichroism and X-ray crystallographic analysis, thus presenting the first direct evidence for the presence of crinine-type alkaloids in the genus Hippeastrum. 


\section{Introduction}

GC-MS has proven to be a useful tool in the identification and quantification of Amaryllidaceae alkaloids (Berkov et al., 2011; Torras-Claveria et al., 2013). This spectroscopic technique has been used with success to assist with the isolation of new or unusual structures from alkaloid-rich extracts by comparing their component electron impact-mass fragmentation spectra (EI-MS) with those of known standards (Berkov et al., 2011; Torras-Claveria et al., 2013). For example, candimine from H. morelianum Lem. and 11b-hydroxygalanthamine from H. papilio (Ravenna) Van Scheepen were both isolated based on prior GC-MS screening of these endemic Brazilian species (de Andrade et al., 2012a). Interestingly, both alkaloids have since exhibited promising anti-Trichomonas vaginalis and acetylcholinesterase (AChE) inhibitory activities (de Andrade et al., 2011; Giordani et al., 2010). Therefore, a similar guided approach is attractive in that it circumvents the need for time and labourintensive chromatographic steps for extracts and alkaloid fractions devoid of new bioactive compounds.

Since the 1970s, X-ray crystallographic and/or circular dichroism (CD) analyses of 5,10bethanophenanthridine alkaloids from Hippeastrum have indicated that they belong exclusively to the haemanthamine series, which are enantiomeric to the crinine series. Earlier, a few crinine-type alkaloids were detected in European Hippeastrum cultivars (Boit and Döpke, 1960; Döpke, 1962), but their absolute configurations have been questioned based on the lack of any tangible evidence, such as CD and X-ray crystallography. These two techniques have since become integral to the unambiguous assignment of the orientation of the 5,10b-ethano bridge in the crinine/haemanthamine series of alkaloids (Bastida et al., 2006; De Angelis and Wildman, 1969; Wagner et al., 1996). In the present study, the use of CD and X-ray crystallographic techniques as well as NMR and GC-MS analysis resulted in the identification of the novel crinine-type alkaloids aulicine (1) and 3-O-methylepimacowine (2) (Fig. 1) along with two new alkaloids [11-oxohaemanthamine (3) and 7-methoxy-Omethyllycorenine (4)] from the Brazilian species Hippeastrum aulicum Herb. and Hippeastrum calyptratum Herb. Nineteen additional known alkaloids were identified in the process, and a complete NMR data set for nerinine (5) and albomaculine (6) is also reported herein. These findings are significant in that they represent the first direct evidence for the presence of crinine-type alkaloids in Hippeastrum. 


\section{Results and discussion}

Of the twenty-three alkaloids identified in H. aulicum and H. calyptratum, thirteen were common to both, while five were unique to either species (Table 1). The major alkaloids detected in H. aulicum were aulicine (1), lycorine (10) and haemanthamine (15), while lycorine (10) was the main constituent present in H. calyptratum. HRESIMS gave a mass of 320.1864 for alkaloid 1, which is expected for the molecular formula $\mathrm{C}_{18} \mathrm{H}_{26} \mathrm{NO}_{4}$ and the theoretical mass (320.1856) for the parent $[\mathrm{M}+\mathrm{H}]^{+}$ion. Its $\mathrm{GC}-$ MS fragmentation pattern was similar to that of the 1,2-dihydroethanophenantridines powellane and deacetylbowdensine (Duffield et al., 1965). As expected, no olefinic proton signals were observed in the ${ }^{1} \mathrm{H}-\mathrm{NMR}$ spectrum of 1 and the only low-field resonance signal was assignable to $\mathrm{H}-7(\delta 6.10, \mathrm{~s})$ due to HSQC correlation with C-7 ( $\delta 101.0$, d), spatial NOESY connectivity to the benzylic $2 \mathrm{H}-6$ protons and HMBC contour correlation with C-6 ( $\delta$ 62.7, t). These data indicated that aulicine (1) possessed a penta-substituted aromatic A-ring and a saturated C-ring moiety. In essence, its 1H-NMR spectrum (Table 2) was similar to that of hippeastidine (Kulhánková et al., 2013; Pacheco et al., 1978; Watson and Zabel, 1982). Although the basic crinane structure of hippeastidine is known with certainty, its absolute stereochemistry still remains unresolved due to its missing CD and X-ray crystallographic data, i.e., it is not clear from the literature whether the compound is of the $\alpha$ - or $\beta$-crinane alkaloid series (Kulhánková et al., 2013; Pacheco et al., 1978; Watson and Zabel, 1982).

A comparison of the ${ }^{1} \mathrm{H}-\mathrm{NMR}$ data of 1 with that of hippeastidine revealed that the only striking differences pertained to the splitting of the H-3 and H-4 protons, both of which are crucial to the stereochemical relationship between the 3-methoxyl substituent and the 5,10b-ethano bridge. The resonance at $\delta 1.21$ ascribed to $\mathrm{H}-4 \beta$ was split into a quartet with an accompanying large coupling constant $(\mathrm{J}=12.4 \mathrm{~Hz}$ ), indicative of two trans-diaxial couplings (with $\mathrm{H}-3$ and $\mathrm{H}-4 \mathrm{a}$ ) and the geminal coupling with $\mathrm{H}-4 \alpha$ (Table 2). Large coupling constants were also observed for H-2 $\beta$. Thus, the H-4 $\beta$ and $\mathrm{H}-2 \beta$ splitting patterns are consistent with a cis relationship between the 3-methoxyl substituent and the 5,10b-ethano bridge. Interestingly, $\mathrm{H}-1 \beta$ was shifted to a lower field when compared to $\mathrm{H}-1 \alpha$ due to its syn-proximity to the hydroxyl group at C-10. The complete NMR data set for aulicine (1) is listed in Table 2. Confirmation of the absolute stereochemistry in 1 was arrived at via $C D$ and X-ray crystallography. The CD spectrum of 1 (Fig. 2A) showed a positive Cotton effect at ca. $250 \mathrm{~nm}$ and negative Cotton effect at ca. $290 \mathrm{~nm}$, in agreement with a crinine-type alkaloid (De Angelis and Wildman, 1969; Wagner et al., 1996). X-ray crystallographic data analysis was carried out using a copper source (see Materials and methods), leading to the unambiguous structural assignment of 1 as a crininetype alkaloid (Fig. 2B).

The new crinine alkaloid 3-O-methyl-epimacowine (2) from $\mathrm{H}$. calyptratum exhibited a parent $[\mathrm{M}+\mathrm{H}]^{+}$ ion at $\mathrm{m} / \mathrm{z} 288.1595$ in its HRESIMS spectrum, thereby suggesting the molecular formula $\mathrm{C}_{17} \mathrm{H}_{22} \mathrm{NO}_{3}$ (calcd. 288.1594). The NMR data of 2 (Table 3) were similar to those of macowine (Nair et al., 2000), with the only notable difference arising from the differential substitution pattern at C-3. An aliphatic methoxyl group was indicated by the chemical shift and splitting pattern of the resonance at $\delta 3.42(3 \mathrm{H}$, s), in accordance with previous studies on 3-substituted alkaloids of the crinine series (Viladomat et al., 1995). A small H-3/H-4 $\beta$ coupling $(\mathrm{J}=4.0 \mathrm{~Hz})$ is consistent with the pseudoaxial orientation for the 3hydroxyl substituent in macowine (Nair et al., 2000). By contrast, in 2 , the large coupling constant $\left(\mathrm{J}_{3,4 \mathrm{~b}}\right.$ $=10.5 \mathrm{~Hz}$ ) suggested a pseudoequatorial disposition for the 3-methoxyl substituent and therefore a cis relationship between this substituent and the $5,10 \mathrm{~b}$-ethano bridge. The bridge orientation was confirmed by $\mathrm{CD}$ analysis, which showed positive and negative Cotton effects at ca. 250 and ca. $290 \mathrm{~nm}$, respectively (Fig. 2C). 
The remaining two new alkaloids, 11-oxohaemanthamine (3) and 7-methoxy-O-methyllycorenine (4), were identified in $\mathrm{H}$. aulicum. The HRESIMS of 3 suggested the molecular formula $\mathrm{C}_{17} \mathrm{H}_{18} \mathrm{NO}_{4}$ for the parent $[\mathrm{M}+\mathrm{H}]^{+}$ion at $\mathrm{m} / \mathrm{z} 300.1239$ (calcd. 300.1230). Its GC-MS fragmentation pattern was similar to that of an alkaloid tentatively assigned to 11-oxohaemanthamine by Kreh et al. (1995). The CD data determined for 3 (see Experimental) were in agreement with those of a crinane-type alkaloid of the $\alpha$ series (Wagner et al., 1996). Characteristic ${ }^{1} \mathrm{H}-\mathrm{NMR}$ signals included the following: (1) two paraoriented aryl protons ( $\delta 6.83$ and 6.52 , for $\mathrm{H}-10$ and $\mathrm{H}-7$, respectively), (2) two AB doublets at $\delta 4.58$ and 3.83, correspondent with the C- 6 benzylic proton system in which $\mathrm{H}-6 \beta$ was assigned to a lower field due to its cis relationship with the nitrogen lone pair, and (3) two vicinal olefinic proton resonances ( $\delta 6.54$ and $\delta 6.21, \mathrm{~J}_{1,2}=10.0 \mathrm{~Hz}$ ), the more shielded of which was assigned to $\mathrm{H}-2$ due to its COSY correlation with $\mathrm{H}-3$ resonant at $\delta 3.84$. The magnitude of the coupling constant between $\mathrm{H}-2$ and $\mathrm{H}-3$ $\left(\mathrm{J}_{2,3}=5.5 \mathrm{~Hz}\right)$ and the small coupling constants between H-3 and both H-4 protons $\left(\mathrm{J}_{3,4 \alpha} \sim 4.0\right.$ and $\mathrm{J}_{3,4 \beta}=2.0 \mathrm{~Hz}$ ) are in agreement with a pseudoequatorial orientation for $\mathrm{H}-3$, thus suggesting a trans relationship between the 3-methoxyl substituent and the 5,10b-ethano bridge (Pabuççuog ${ }^{-1 u}$ et al., 1989). The NMR data for 3 (Table 4) are consistent with 11-oxohaemanthamine, which was recently synthesised by Cedrón et al. (2012). The isolation of 3 from a natural source is reported here for the first time.

Homolycorine-type alkaloids bearing trimethoxyaryl substituents were originally reported during the 1950s (Boit and Döpke, 1957; Briggs et al., 1956). The mass fragmentation pattern of 7-methoxy-Omethyllycorenine (4) was in agreement with patterns typical for homolycorine-type alkaloids (Kreh et al., 1995; Schnoes et al., 1962). The HRESIMS data for 4 was consistent with the molecular formula $\mathrm{C}_{20} \mathrm{H}_{28} \mathrm{NO}_{5}$ for the parent ion $[\mathrm{M}+\mathrm{H}]^{+}$at $\mathrm{m} / \mathrm{z} 362.1964$ (calcd. 362.1962). The ${ }^{1} \mathrm{H}-\mathrm{NMR}$ data of 4 (Table 5) were similar to of the data for O-methyllycorenine, originally reported by Codina et al. (1993) and differing only by the presence of a third aromatic methoxyl group resonance at $\delta 3.89(3 \mathrm{H}, \mathrm{s})$. Thus, the 7,8,9-trimethoxyaryl substitution in 4 was confirmed by the NOESY correlation evident between $\mathrm{H}$ 10 and the N-methyl group. The C-7 and C-8 methoxyl carbon resonances ( $\delta 61.5$ and $\delta 61.2$, respectively) were diagnostically downfield shifted from that of C-9 $(\delta 56.6)$, as previously indicated (Bastida et al., 1992). The large coupling constant $\mathrm{J}_{4 \mathrm{a}, 10 \mathrm{~b}}=10.0 \mathrm{~Hz}$ confirmed a trans-diaxial relationship between $\mathrm{H}-4 \mathrm{a}$ and $\mathrm{H}-10 \mathrm{~b}$. A cis B/C ring junction was suggested based on the small value of the coupling constant measured between $\mathrm{H}-1$ and $\mathrm{H}-10 \mathrm{~b}(\mathrm{~J}=2.0 \mathrm{~Hz})$. NOESY correlation between 6-OMe and $\mathrm{H}-1$ confirmed the $\beta$-orientation for $\mathrm{H}-6$, a feature characteristic of hemiacetal functionalised homolycorine alkaloids (Bastida et al., 2006; Codina et al., 1992). The complete NMR data of 4 are provided in Table 5.

The structures of nerinine (5) and albomaculine (6) were confirmed by comparing their respective physical and spectroscopic data with the data available in the literature (Berkov et al., 2011; Codina et al., 1992; Jeffs and Hawksworth, 1963; Kreh et al., 1995; Schnoes et al., 1962). However, in both instances, these were found to be incomplete and are therefore comprehensively presented here in the Experimental section as well as in Tables 6 and 7.

Aulicine (1) ${ }^{1}$ : white crystals; $[\alpha] \mathrm{D}^{24}-2,3$ (c 0.38, CHCl3); $\mathrm{CD}[\Theta]^{20} \lambda:[\Theta] 255^{+} 1043,[\Theta] 279-768$; UV $(\mathrm{MeOH}) \lambda_{\max }(\log \varepsilon) 233$ (3.50), 273 (2.70) nm; IR (CHCl3) v $v_{\max } 3291,2931,2858,1605,1577,1495$, 1455, 1424, 1126, $1103 \mathrm{~cm}^{-1}$; 1H-NMR (CDCl3, $\left.400 \mathrm{MHz}\right)$ and ${ }^{13} \mathrm{C}-\mathrm{NMR}\left(\mathrm{CDCl}_{3}, 100 \mathrm{MHz}\right)$ see Table 2; EIMS data shown in Table 1; HRESIMS of $[\mathrm{M}+\mathrm{H}]^{+} \mathrm{m} / \mathrm{z} 320.1864$ (calcd for $\mathrm{C}_{18} \mathrm{H}_{26} \mathrm{NO}_{4}$, 320.1856). 
167 3-O-Methyl-epimacowine (2): white needles; $[\alpha]_{\mathrm{D}}{ }^{22}-47$ (c $\left.0.42, \mathrm{CHCl}_{3}\right)$; $\mathrm{CD}[\Theta]^{20}{ }_{1}:[\Theta] 254+2528$, $168[\Theta] 290$-2215; UV (MeOH) $\lambda \max (\log \varepsilon) 230(3.31), 288$ (3.23) nm; IR $\left(\mathrm{CHCl}_{3}\right) v_{\max } 2925,2854,1507$, 169 1461, 1312, 1277, 1219, 1098, $754 \mathrm{~cm}^{-1}$; ${ }^{1} \mathrm{H}-\mathrm{NMR}\left(\mathrm{CDCl}_{3}, 500 \mathrm{MHz}\right)$ and ${ }^{13} \mathrm{C}-\mathrm{NMR}\left(\mathrm{CDCl}_{3}, 125\right.$ $170 \mathrm{MHz}$ ) see Table 3; EIMS data shown in Table 1; HRESIMS of $[\mathrm{M}+\mathrm{H}]^{+} \mathrm{m} / \mathrm{z} 288.1595$ (calcd for $\left.171 \mathrm{C}_{17} \mathrm{H}_{22} \mathrm{NO}_{3}, 288.1594\right)$.

172 11-Oxohaemanthamine (3): white needles; $[\alpha]_{\mathrm{D}}{ }^{20}+44\left(\mathrm{c} 0.12, \mathrm{CHCl}_{3}\right) ; \mathrm{CD}[\Theta]^{20} \lambda:[\Theta] 255-3429$, $173[\Theta]_{320}+3298 ; \mathrm{UV}(\mathrm{MeOH}) \lambda_{\max }(\log \varepsilon) 250$ (2.94), 295 (2.92), 313 (2.82) nm; IR $\left(\mathrm{CHCl}_{3}\right) \lambda_{\max } 2924$, $1742854,1744,1503,1481,1463,1377,1238,1086,1038 \mathrm{~cm}^{-1} ;{ }^{1} \mathrm{H}-\mathrm{NMR}\left(\mathrm{CDCl}_{3}, 500 \mathrm{MHz}\right)$ see Table 4; 175 EIMS data shown in Table 1; HRESIMS of $[\mathrm{M}+\mathrm{H}]^{+} \mathrm{m} / \mathrm{z} 300.1239$ (calcd for $\left.\mathrm{C}_{17} \mathrm{H}_{18} \mathrm{NO} 4,300.1230\right)$.

176 7-Methoxy-O-methyllycorenine (4): amorphous solid; $[\alpha] \mathrm{D}^{23}+31$ (c $\left.0.33, \mathrm{CHCl}_{3}\right)$; UV (MeOH) $177 \lambda_{\max }(\log \varepsilon) 230$ (3.55), 270 (2.75) nm; IR $\left(\mathrm{CHCl}_{3}\right) v_{\max }$ 2924, 2853, 2783, 1601, 1460, 1336, 1128, 178 1053, 1025; ${ }^{1} \mathrm{H}-\mathrm{NMR}\left(\mathrm{CDCl}_{3}, 500 \mathrm{MHz}\right)$ and ${ }^{13} \mathrm{C}-\mathrm{NMR}\left(\mathrm{CDCl}_{3}, 125 \mathrm{MHz}\right)$ see Table 5; EIMS data 179 shown in Table 1; HRESIMS of $[\mathrm{M}+\mathrm{H}]^{+} \mathrm{m} / \mathrm{z} 362.1964$ (calcd for $\mathrm{C}_{20} \mathrm{H}_{28} \mathrm{NO} 5,362.1962$ ).

180 Nerinine (5): amorphous solid; $[\alpha]_{\mathrm{D}}^{23}+40$ (c 0.33, $\left.\mathrm{CHCl}_{3}\right)$; UV (MeOH) $\lambda_{\max }(\log \varepsilon) 232$ (3.59), 273 $181(2.89) \mathrm{nm}$; IR $\left(\mathrm{CHCl}_{3}\right) v_{\max } 3145,2918,2849,1587,1460,1410,1336,1243,1122,1018 \mathrm{~cm}^{-1} ;{ }^{1} \mathrm{H}-$ $182 \mathrm{NMR}\left(\mathrm{CDCl}_{3}, 400 \mathrm{MHz}\right)$ and ${ }^{13} \mathrm{C}-\mathrm{NMR}\left(\mathrm{CDCl}_{3}, 100 \mathrm{MHz}\right)$ see Table 6; EIMS data shown in Table 1; 183 HRESIMS of $[\mathrm{M}+\mathrm{H}]^{+} \mathrm{m} / \mathrm{z} 348.1807$ (calcd for $\mathrm{C}_{19} \mathrm{H}_{26} \mathrm{NO}$ 5, 348.1805).

184 Albomaculine (6): amorphous solid; $[\alpha]_{\mathrm{D}}^{23}+25$ (c 0.95, $\left.\mathrm{CHCl}_{3}\right)$; $\mathrm{UV}(\mathrm{MeOH}) \lambda_{\max }(\log \varepsilon) 222$ (4.26), 185266 (3.86), $298(3.34) \mathrm{nm}$; IR (CHCl3) $v_{\max } 2929,2849,2783,1725,1592,1334,1254,1111,1022 \mathrm{~cm}^{-}$ $186{ }^{1}$; ${ }^{1} \mathrm{H}-\mathrm{NMR}(\mathrm{CDCl} 3,400 \mathrm{MHz})$ and ${ }^{13} \mathrm{C}-\mathrm{NMR}\left(\mathrm{CDCl}_{3}, 100 \mathrm{MHz}\right)$ see Table 7; EIMS data shown in 187 Table 1; HRESIMS of $[\mathrm{M}+\mathrm{H}]^{+} \mathrm{m} / \mathrm{z} 346.1651$ (calcd for $\mathrm{C}_{19} \mathrm{H}_{24} \mathrm{NO}_{5}, 346.1649$ ). 
190

191 In summary, phytochemical investigation of H. aulicum and H. calyptratum led to the identification of

19223 Amaryllidaceae alkaloids. Of these alkaloids, aulicine, 3-O-methyl-epimacowine, 11193 oxohaemanthamine and 7-methoxy-O-methyllycorenine are reported here for the first time. The 194 structures of these alkaloids were determined by physical and spectroscopic methods, including GC195 MS, NMR, CD and X-ray crystallography. The identification of the b-crinane alkaloids aulicine and 3196 O-methyl-epimacowine in Hippeastrum is of considerable biosystematic significance because previous 197 findings have revealed that all crinane compounds from this genus are reminiscent of the a-series. Efforts 198 to further delineate this anomaly via targeted studies of other species of Hippeastrum are presently 199 underway in our laboratories. 


\section{Materials and methods}

\subsection{General procedure}

NMR spectra were recorded on a Mercury $400 \mathrm{MHz}$ (Palo Alto, CA, USA) or a Varian $500 \mathrm{MHz}$ (Palo Alto, CA, USA) instrument using CDCl3 (CD3OD for 4 and 10) as the solvent and TMS as the internal standard. Chemical shifts are reported in d units (ppm) and coupling constants (J) in Hz. The GC-MS spectra were obtained on an Agilent 6890N GC 5975 inert MSD operating in the EI mode at $70 \mathrm{eV}$ (Agilent Technologies, Santa Clara, CA, USA) using a DB5 MS column (30 m x $0.25 \mathrm{~mm} \times 0.25 \mathrm{~lm}$, Agilent Technologies). The temperature program was as follows: $100-180{ }^{\circ} \mathrm{C}$ at $15^{\circ} \mathrm{C} \mathrm{min}^{-1}, 1 \mathrm{~min}$ hold at $180^{\circ} \mathrm{C}$ and $180-300{ }^{\circ} \mathrm{C}$ at $5^{\circ} \mathrm{C} \mathrm{min}^{-1}$ and $40 \mathrm{~min}$ hold at $300^{\circ} \mathrm{C}$. The injector temperature was $280^{\circ} \mathrm{C}$. The flow rate of carrier gas (helium) was $0.8 \mathrm{ml} \mathrm{min}^{-1}$, and the split ratio was 1:20. HRESIMS spectra were obtained on a LC/MSD-TOF (2006) mass spectrometer (Agilent Technologies, Santa Clara, CA, USA) by direct injection of the compounds dissolved in $\mathrm{H} 2 \mathrm{O}-\mathrm{MeCN}$ (1:1). Optical rotations were carried out on a Perkin-Elmer 241 polarimeter (Waltham, MA, USA). A Jasco-J-810 Spectrophotometer (Easton, MD, USA) was used to run CD spectra, all recorded in MeOH. UV spectra were obtained on a DINKO UV2310 instrument (Barcelona, Spain) and IR spectra were recorded on a Nicolet Avatar 320 FT-IR spectrophotometer (Waltham, MA, USA). Silica gel (Kieselgel - mesh 0.15/0.30, Val-de-Reuil, France) was used for all vacuum liquid chromatography procedures (VLC). For thin layer chromatography (TLC), silica gel F254 was used as the stationary phase with a plate dimension of $20 \mathrm{~cm} \times 20 \mathrm{~cm} \times 0.20 \mathrm{~mm}$ for analytical TLC and $20 \mathrm{~cm} \times 20 \mathrm{~cm} \times 0.25 \mathrm{~mm}$ for semipreparative TLC (SPTLC) (Val-de-Reuil, France). Exclusion chromatography was carried out using a Sephadex LH-20 (Uppsala, Sweden).

\subsection{Plant material}

Bulbs of H. aulicum Herb. and H. calyptratum Herb. were collected in October 2011 during the flowering period from a population located in Cunha City, Sao Paulo Province (Brazil). Both species were identified by Mr. Mauro Peixoto and Dr. Jullie Dutilh (University of Campinas, Unicamp, Brazil). The voucher specimens of $\mathrm{H}$. aulicum were deposited in the herbarium at the Plantarum Institute under the reference number HPL 13043. The voucher specimens of H. calyptratum were deposited in the Herbarium of the University of Campinas (Unicamp, Brazil) under the reference number UEC 59648.

\subsection{Extraction and isolation of alkaloids}

Dried bulbs $(370 \mathrm{~g})$ of $\mathrm{H}$. aulicum were crushed and thrice extracted for $48 \mathrm{~h}$ with $\mathrm{MeOH}$ at room temperature, and the combined macerate was filtered and evaporated under reduced pressure. The crude extract $(90 \mathrm{~g})$ was acidified with sulphuric acid (2\%) to pH 2 and extracted with Et2O (4x $250 \mathrm{ml})$ and EtOAc $(4 \times 250 \mathrm{ml})$ to remove neutral material. The aqueous solution was basified with ammonia $(25 \%)$ up to $\mathrm{pH} 10$ and extracted with $\mathrm{n}$-hexane $(8 \times 250 \mathrm{ml})$ to give extract IA $(0.86 \mathrm{~g})$. Another extraction using EtOAc $(8 \times 250 \mathrm{ml})$ produced extract IIA $(2.0 \mathrm{~g})$, wherein lycorine (10) precipitated spontaneously. A final extraction using EtOAc-MeOH $(3: 1,3$ x $250 \mathrm{ml})$ showed negative results for alkaloids as confirmed by Dragendorff's reagent stain and GC-MS. 
Extract IA was subjected to VLC $(2.5 \times 6 \mathrm{~cm})$ on silica gel $(10 \mathrm{~g})$, starting with n-hexane $(100 \%)$, gradually enriching with EtOAc $(0 \rightarrow 100 \%)$, and finally with $\mathrm{MeOH}(0 \rightarrow 30 \%)$. A total of $150,50 \mathrm{ml}$ fractions were collected, monitored by analytical TLC (Dragendorff's reagent, UV light k $254 \mathrm{~nm}$ ) and combined after TLC analysis. Nerinine $(5,15 \mathrm{mg})$ was isolated by precipitation of fractions $65-86$, and the supernatant was submitted to SPTLC (EtOAc-Me2- CO-n-hexane-MeOH - 6:2:1:1, in NH3 atmosphere), which allowed for the isolation of 7-methoxy-O-methyllycorenine $(4,6.5 \mathrm{mg})$ and galanthamine (13, $10 \mathrm{mg}$ ). Fractions $87-118$ gave haemanthamine (15) and aulicine (1) again by precipitation and further purification by SPTLC (n-hexane-EtOAc-Me2CO-MeOH-n-BuOH 4:3:3:2:1, in NH3 atmosphere). The supernatant was oaded onto a VLC column $(1.5 \times 4 \mathrm{~cm})$ of silica gel $(3 \mathrm{~g})$, using nhexane $(100 \%)$ as the starting solvent, gradually enriched with EtOAc $(0 ? 100 \%)$, and finally with $\mathrm{MeOH}(0 ? 30 \%)$, ultimately yielding 250 fractions (each $10 \mathrm{ml}$ ). After combining the fractions according to the TLC profiles, 11-oxohaemanthamine $(3,5.3 \mathrm{mg})$ was isolated from pooled fractions 93-113 using SPTLC (n-hexane-Me2CO-EtOAc-MeOH - 15:10:5:2, in NH3 atmosphere). Fractions 222-250 were combined and subjected to SPTLC (n-hexane-EtOAc-Me2CO-MeOH-n$\mathrm{BuOH}-4: 3: 3: 2: 1$, in NH3 atmosphere), after which 1 and 15 were again isolated.

Alkaloid 15 precipitated spontaneously from extract IIA after resuspension in $\mathrm{MeOH}$. The supernatant (700 mg) was purified by silica gel VLC ( 2 × $6 \mathrm{~cm}$ column, $10 \mathrm{~g})$, starting with n-hexane $(100 \%)$, gradually enriching with EtOAc $(0 \rightarrow 100 \%)$ and finally with $\mathrm{MeOH}(0 \rightarrow 30 \%)$, ultimately yielding 200 fractions $(50 \mathrm{ml}$ each) that were then pooled according to TLC profile analysis. SPTLC (n-hexaneEtOAc-Me2CO-MeOH-n-BuOH - 4:3:3:2:1, in NH3 atmosphere) of fractions 134-190 gave 1 (152 $\mathrm{mg}), 15(161.1 \mathrm{mg})$ and $10(135 \mathrm{mg})$, while a small quantity of tazettine $(19,3.2 \mathrm{mg})$ precipitated from fractions 191-205. GC-MS spectra of the remaining fractions indicated the presence of only known compounds (Table 1), which therefore precluded the need for further chromatographic analyses.

Dried bulbs (135 g) of $\mathrm{H}$. calyptratum were crushed and extracted by stirring with $\mathrm{MeOH}$ at room temperature for $48 \mathrm{~h}$ (repeating three times), and the combined macerate was filtered and evaporated under reduced pressure. The crude extract (50 g) was acidified with sulphuric acid (2\%) to pH 2 and extracted with Et2O (4 x $250 \mathrm{ml})$ and EtOAc $(4 \times 250 \mathrm{ml})$ to remove neutral material. The aqueous solution was then basified with ammonia (25\%) up to $\mathrm{pH} 10$ and extracted with n-hexane $(8 \times 250 \mathrm{ml})$ to give extract IC $(100 \mathrm{mg})$. Extraction with EtOAc $(8 \times 250 \mathrm{ml})$ gave extract IIC $(300 \mathrm{mg})$. A final extraction using EtOAc-MeOH (3:1) showed negative results for alkaloids as confirmed by Dragendorff's reagent and GC-MS analysis.

Extracts IC and IIC (400 mg) were combined after GC-MS showed them to be similar. Alkaloid 10 precipitated after re-suspension in $\mathrm{MeOH}$ and the supernatant was purified by VLC $(2.5 \mathrm{x} 4 \mathrm{cmcolumn}$, $10 \mathrm{~g}$ of silica gel) using the same solvent systemas that for H. aulicum. Alkaloid $10(115 \mathrm{mg})$ precipitated directly from fractions $93-140$. Fractions $71-170$ were combined $(250 \mathrm{mg})$ and subjected to VLC $(1.5 \mathrm{x}$ $4 \mathrm{~cm}$ column $)$ in silica gel $(3 \mathrm{~g})$ using $\mathrm{n}$-hexane $(100 \%)$ followed by EtOAc $(0 \rightarrow 100 \%)$ and finally with $\mathrm{MeOH}(0 \rightarrow 30 \%)$, ultimately yielding 250 fractions ( $10 \mathrm{ml}$ each). Only fractions $145-200$ (110 $\mathrm{mg}$ ) showed alkaloids with unknown GC-MS fragmentation patterns and were therefore selected for further VLC, which was carried out on silica gel (3 g) using a 1.54 cmcolumn, starting with nhexane $(100 \%)$ and increasing solvent polarity with EtOAc $(0 \rightarrow 50 \%)$. Thereafter, $\mathrm{CHCl}_{3}$ and EtOAc were gradually added until a $\mathrm{CHCl}_{3}-\mathrm{EtOAc}$ ration of 1:1 was reached. Finally, the system was gradually enriched with $\mathrm{MeOH}(0 ? 30 \%)$, ultimately yielding 200 fractions (10ml each). Albomaculine $(6,19.3 \mathrm{mg})$ was isolated from fractions $69-88$ by SPTLC ( $\mathrm{Me}_{2} \mathrm{CO}-\mathrm{CH}_{2} \mathrm{Cl}_{2}-3: 10$, in $\mathrm{NH}_{3}$ atmosphere) together with 2a,7-dimethoxyhomolycorine (9, $3.2 \mathrm{mg})$. Likewise, 3-Omethyl-epimacowine (2,18.3mg) and alkaloid $13\left(7.7 \mathrm{mg}\right.$ ) were isolated from fractions 89-148 using SPTLC (EtOAc- $\mathrm{Me}_{2} \mathrm{CO}-\mathrm{CH}_{2} \mathrm{Cl}_{2}-$ $\mathrm{MeOH}-3: 1: 1: 0.5$, in NH3 atmosphere). 
The alkaloids were identified by comparing their GC-MS spectra and Kovats retention indices (RI) with our library database. This library has been regularly updated with alkaloids isolated and unequivocally identified via physical and spectroscopic means (Berkov et al., 2008; de Andrade et al., 2011, 2012b; Giordani et al., 2011; Llabrés et al., 1986). NMR data for the known alkaloids described here closely matched those reported elsewhere (Bastida et al., 2006; Kobayashi et al., 1980). Mass spectra were deconvoluted using the AMDIS 2.64 software (NIST) (WA, USA), and RIs were recorded using a standard n-hydrocarbon calibration mixture (C9-C36). The proportion of individual components in the alkaloid fractions are expressed as a percentage of total alkaloid content. GC-MS peak areas are dependent on the concentration of the injected alkaloid as well as the intensity of its mass spectral fragmentation. Although the data given in Table 1 are not representative of a validated alkaloid quantification method, these data can be used for relative comparison purposes.

\subsection{Crystals of aulicine (1)}

Compound 1 was dissolved in a $\mathrm{MeOH}-\mathrm{CHCl}_{3}$ (1:1) mixture under a pentane atmosphere. After 14 days standing at $\sim 5^{\circ} \mathrm{C}$, small crystals of 1 formed and were selected for X-ray crystallography.

\section{6. $X$-ray analysis}

A prismatic crystal $\left(\begin{array}{lll}0.1 & 0.1 & 0.2 \mathrm{~mm}\end{array}\right)$ was selected and mounted on a Bruker D8 Venture four-circle diffractometer (Karlsruhe, Germany). Intensities were collected with a multilayer monochromator and a Cu high brilliance microfocus sealed tube using the / and x scan-technique. A total of 24158 reflections were measured in the range of $2.936 \mathrm{~h} 674.32$, with 6377 of the reflections non-equivalent by symmetry (Rint(on I) $=0.031$ ). Overall, 6028 reflections were assumed to be as observed by applying the condition $\mathrm{I}>2 \mathrm{r}(\mathrm{I})$. Lorentz-polarisation and absorption corrections were performed.

The structure was solved by direct methods, using the SHELXS computer program (and refined by a full-matrix least-squares method with the SHELX97 computer program (Sheldrick, 2008)) and 24158 reflections, (very negative intensities were not assumed). The function minimised was $\sum w \|\left.\mathrm{Fo}\right|^{2} \mid \mathrm{Fc}^{2}$ $\left.\right|^{2}$, where $\mathrm{w}=\left[\rho^{2}(\mathrm{I})+(0.0343 \mathrm{P}) 2+0.8335 \mathrm{P}\right]^{-1}$, and $\mathrm{P}=\left(|\mathrm{Fo}|^{2}+2|\mathrm{Fc}|^{2}\right) / 3, \mathrm{f}, \mathrm{f}$ and $\mathrm{f}^{\prime}$ ' were taken from the International Tables of X-ray Crystallography (1974). All $\mathrm{H}$ atoms were computed and refined using a riding model, with an isotropic temperature factor equal to 1.2 times the equivalent temperature factor of the atoms that are linked. The final R(on F) factor was 0.0298 , wR(on $|\mathrm{F}|^{2}$ ) $=0.074$ and goodness of fit $=1.042$ for all observed reflections. The number of refined parameters was 423 . Max. shift/esd $=$ 0.00 , Mean shift/esd $=0.00$. Max. and min. peaks in the final difference synthesis were 0.215 and 0.164 $\mathrm{e} \AA^{-3}$, respectively. 


\section{ACKNOWLEDGEMENTS}

330

331 The authors are grateful to the Generalitat de Catalunya (2009 - SGR1060) for the financial support of this research and to the SCT-UB personnel for technical assistance. Special thanks is given to Mr. Mauro Peixoto for the collection of plant material. J.A.S.Z. acknowledges CNPq (Brazil) for a research fellowship. J.P.A. thanks the Agencia Española de Cooperación Internacional para el Desarollo (BECAS-MAEC-AECID) for a doctoral fellowship. 


\section{References}

Bastida, J., Codina, C., Viladomat, F., Rubiralta, M., Quirion, J.C., Weniger, B., 1992. Narcissus alkaloids, XV: Roserine from Narcissus pallidulus. J. Nat. Prod. 55, 134-136.

Bastida, J., Lavilla, R., Viladomat, F., 2006. Chemical and biological aspects of Narcissus alkaloids. In: Cordell, G.A. (Ed.), The Alkaloids, vol. 63. Elsevier Inc., Amsterdam, pp. 87-179.

Berkov, S., Codina, C., Viladomat, F., Bastida, J., 2008. N-Alkylated galanthamine derivatives: potent acetylcholinesterase inhibitors from Leucojum aestivum. Bioorg. Med. Chem. Lett. 18, 22632266 .

Berkov, S., Bastida, J., Sidjimova, B., Viladomat, F., Codina, C., 2011. Alkaloid diversity in Galanthus elwesii and Galanthus nivalis. Chem. Biodivers. 8, 115-130. Boit, H.G., Döpke, W., 1957. Alkaloids of the Amaryllidaceae. XVIII. Alkaloids from Urceolina, Hymenocallis, Elisena, Calostemma, Eustephia, and Hippeastrum. Chem. Ber. 90, 1827-1830.

Boit, H.G., Döpke, W., 1960. New alkaloids from Hippeastrum hybrids and Nerine flexuosa. Naturwissenschaften 47, 470-471.

Briggs, C.K., Highet, P.F., Highet, R.J., Wildman, W.C., 1956. Alkaloids of the Amaryllidaceae. VII. Alkaloids containing the hemiacetal or lactone group. J. Am. Chem. Soc. 78, 2899-2904.

Cedrón, J.C., Gutiérrez, D., Flores, N., Ravelo, Á.G., Estévez-Braun, A., 2012. Synthesis and antimalarial activity of new haemanthamine-type derivatives. Bioorg. Med. Chem. 20, 54645472 .

Codina, C., Viladomat, F., Bastida, J., Rubiralta, M., Quirion, J.C., 1992. 2D NMR studies of lycorenine as a model for the structural assignment of lycoreninetype alkaloids. Nat. Prod. Lett. 1, 85-92.

Codina, C., Bastida, J., Viladomat, F., Fernández, J.M., Bergoñón, S., Rubiralta, M., Quirion, J.C., 1993. Alkaloids from Narcissus muñozii-garmendiae. Phytochemistry 32, 1354-1356.

de Andrade, J.P., Berkov, S., Viladomat, F., Codina, C., Zuanazzi, J.A.S., Bastida, J., 2011. Alkaloids from Hippeastrum papilio. Molecules 16, 7097-7104.

de Andrade, J.P., Pigni, N.B., Torras-Claveria, L., Guo, Y., Berkov, S., Reyes-Chilpa, R., El Amrani, A., Zuanazzi, J.A.S., Codina, C., Viladomat, F., Bastida, J., 2012a. Alkaloids from the Hippeastrum genus: chemistry and biological activity. Rev. Latinoam. Quim. 40, 83-98.

de Andrade, J.P., Pigni, N.B., Torras-Claveria, L., Berkov, S., Codina, C., Viladomat, F., Bastida, J., 2012b. Bioactive alkaloids from Narcissus broussonetii: mass spectral studies. J. Pharm. Biomed. Anal. 70, 13-25.

De Angelis, G.G., Wildman, W.C., 1969. Circular dichroism studies - I. A quadrant rule for the optically active aromatic chromophore in rigid polycyclic systems. Tetrahedron 25, 5099-5112.

Döpke, W., 1962. Alkaloids of the Hippeastrum type. Arch. Pharm. Ber. Dtsch. Pharm. Ges. 295, 920924.

Duffield, A.M., Aplin, R.T., Budzikiewicz, H., Djerassi, C., Murphy, C.F., Wildman, W.C., 1965. Mass spectrometry in structural and stereochemical problems. LXXXII. A study of the fragmentation of some Amaryllidaceae alkaloids. J. Am. Chem. Soc. 87, 4902-4912. 
Giordani, R.B., Vieira, P.B., Weizenmann, M., Rosember, D.B., Souza, A.P., Bonorino, C., de Carli, G.A., Bogo, M.R., Zuanazzi, J.A.S., Tasca, T., 2010. Candimine-induced cell death of the amitochondriate parasite Trychomonas vaginalis. J. Nat. Prod. 73, 2019-2023.

Giordani, R.B., de Andrade, J.P., Verli, H., Dutilh, J.H., Henriques, A.T., Berkov, S., Bastida, J., Zuanazzi, J.A.S., 2011. Alkaloids from Hippeastrum morelianum Lem. (Amaryllidaceae). Magn. Reson. Chem. 49, 668-672.

International Tables of X-ray Crystallography, 1974. Ed. Kynoch Press, Birmingham, vol. IV, pp 99 $100,149$.

Jeffs, P.W., Hawksworth, W.A., 1963. Aromatic oxygenation patterns of some trioxyaryl Amaryllidaceae alkaloids belonging to the hemi-acetal and lactone group. Tetrahedron Lett. 4, 217-223.

Kobayashi, S., Kihara, M., Shingu, T., Shingu, K., 1980. Transformation of tazettine to pretazettine. Chem. Pharm. Bull. 80, 2924-2932.

Kreh, M., Matusch, R., Witte, L., 1995. Capillary gas chromatography-mass spectrometry of Amaryllidaceae alkaloids. Phytochemistry 38, 773-776.

Kulhánková, A., Cahlíková, L., Novák, Z., Macáková, K., Kunes, J., Opletal, L., 2013 Alkaloids from Zephyranthes robusta Baker and their acetylcholinesterase- and butyrylcholinesteraseinhibitory activity. Chem. Biodivers. 10, 1120-1127.

Llabrés, J.M., Viladomat, F., Bastida, J., Codina, C., Serrano, M., Rubiralta, M., Feliz, M., 1986. Two alkaloids from Narcissus requienii. Phytochemistry 25, 1453-1459.

Nair, J.J., Machocho, A.K., Campbell, W.E., Brun, R., Viladomat, F., Codina, C., Bastida, J., 2000. Alkaloids from Crinum macowanii. Phytochemistry 54, 945-950.

Pabuççuog־lu, V., Richomme, P., Gözler, T., Kivçak, B., Freyer, A.J., Shamma, M., 1989. Four new crinine-type alkaloids from Sternbergia species. J. Nat. Prod. 52, 785-791.

Pacheco, P., Silva, M., Steglich, W., 1978. Alkaloids of Chilean Amaryllidaceae I. Hippeastidine and epi-homolycorine two novel alkaloids. Rev. Latinoam. Quim. 9, 28-32.

Schnoes, H.K., Smith, D.H., Burlingame, A.L., Jeffs, P.W., Döpke, W., 1962. Mass spectra of Amaryllidaceae alkaloids - the lycorenine series. Tetrahedron 24, 2825-2837.

Sheldrick, G.M., 2008. A program for automatic solution of crystal structure refinement. Acta Crystallogr. A64, 112-221.

Torras-Claveria, L., Berkov, S., Codina, C., Viladomat, F., Bastida, J., 2013. Daffodils as potential crops of galanthamine. Assessment of more than 100 ornamental varieties for their alkaloid content and acetylcholinesterase inhibitory activity. Ind. Crops Prod. 43, 237-244.

Viladomat, F., Codina, C., Bastida, J., Mathee, S., Campbell, W.E., 1995. Further alkaloids from Brunsvigia josephinae. Phytochemistry 40, 961-965.

Wagner, J., Pham, H.L., Döpke, W., 1996. Alkaloids from Hippeastrum equestre Herb. -5. Circular dichroism studies. Tetrahedron 52, 6591-6600.

Watson, W.H., Zabel, V., 1982. Hippeastidine C17H23O4N. Cryst. Struct. Commun. 11, 157-162. 
415 Legends to figures

416

417 Figure 1. Alkaloids identified in H. aulicum $\left({ }^{\mathrm{a}}\right)$ and H. calyptratum $\left({ }^{\mathrm{b}}\right)$.

418

419 Figure 2. CD spectrum (A) and ORTEP projection (B) of alkaloid 1. CD spectrum (C) of alkaloid 2. 420

421 
422 Table 1. GC-MS data for H. aulicum and H. calyptratum alkaloids. Values are expressed as a relative 423 percentage of TIC.

\begin{tabular}{|c|c|c|c|c|c|c|c|}
\hline \multirow[t]{2}{*}{ Alkakaid } & \multirow[t]{2}{*}{ R } & \multicolumn{2}{|c|}{$\underline{H}$ aulicumn (x) } & \multicolumn{2}{|c|}{$\underline{H \text { calyptratum }}(x)$} & \multirow[t]{2}{*}{$\mathbf{M}^{+}$} & \multirow[t]{2}{*}{ MS } \\
\hline & & IA & IIA & ic & IIC & & \\
\hline Ismine $(\mathbf{2 1})^{*}$ & 2280 & - & $\operatorname{tr}^{e}$ & - & 0.45 & $257(35)$ & $239(100), 211(6,196(8), 168(6), 1543), 106(4), 77(3)$ \\
\hline Trisphueridine $(\mathbf{2 2})^{*}$ & 2282 & tr & a.61 & - & tr & $223(100)$ & $222(38), 167(8), 165(9), 164(14), 138(20), 137(9), 111(13)$ \\
\hline Galanthamine (13) & 2395 & 11.26 & 1.75 & 12.93 & 660 & $287(83)$ & $280(100,270(13), 24424,230(12), 216(33), 17427), 115(12)$ \\
\hline Vittatine $(17)^{*}$ & 2472 & - & 0.34 & - & - & $271(100)$ & 228(25), 199(95), 187(85, 173(28), 128(32), 115(33) $58(22)$ \\
\hline 3-0-Methyl-epimxawine $(2)^{*}$ & 2477 & - & - & 14.68 & 13.45 & $287(100)$ & $272\langle 39), 25 \&(34), 217(71,203(21), 174,18), 157(18,128(14)$ \\
\hline Narwedine (14) & 2483 & 098 & - & an2 & tr & $285(84)$ & $284100,242(18), 216(20,199(18), 174(31), 128(16), 115(16)$ \\
\hline Galanthindal (23) & 2487 & - & - & - & 1.11 & $281(100)$ & $280(7), 264(13), 263(17), 262(20), 252(15), 2047), 1(14), 132(8)$ \\
\hline Anhydrolyorine (12) & 2501 & - & 1.84 & - & 531 & $251(43)$ & $250(100), 192(13), 191(11,165(4), 16433,139(2), 124(7)$ \\
\hline Nerinine $(5)^{+}$ & 2509 & 238 & 575 & 036 & 091 & $34 \lambda(<1)$ & $222(1), 207(2), 179(1), 164(1), 110(8), 109(100), 108(18), 942)$ \\
\hline 8-0-Demethylmaritidine $(\mathbf{1 6})^{+}$ & 2510 & - & 241 & - & tr & $273(100)$ & $250(22), 23 \alpha(20,201(83), 189(42), 174(22), 128(23), 115(24)$ \\
\hline 7-Methaxy- 0 -methyllycarenine $(4)^{*}$ & 2538 & 1.60 & - & - & - & $361(<1)$ & $330(8,221(10), 191(2,110(8), 109(100), 108(15), 942), 83(2)$ \\
\hline 11-Owohademanthamine (3) & $25 e 5$ & 1.50 & tr & - & - & $299(<1)$ & $271(100), 270(37), 240(10), 238(10), 211(23), 181(7), 152(20)$ \\
\hline Aulicine $(1)^{*}$ & 2607 & 43.65 & 5.47 & - & - & $319(100)$ & $304(19), 288(37), 246(18), 233(73), 218(19,200(26), 163(7)$ \\
\hline Haemanthamine $(15)^{*}$ & 2641 & 303 & 7158 & - & - & $301(14)$ & $272(100), 257(10), 240(16), 181(21), 214(12), 211(14), 128(8)$ \\
\hline Tarettine (19)/Pretazettine $(20)^{4^{*}}$ & 2653 & tr & tr & - & 0.62 & $331(31)$ & $31 Q(15), 298(23), 247(100,230(12), 201(15), 181(11), 15227)$ \\
\hline 11-Hydraxyvittatine (18) & 2728 & - & - & - & 950 & $287(5)$ & $258(100), 211(15), 18 \times(20), 181(23), 153(13), 128(24), 115(23)$ \\
\hline Lycarine $(\mathbf{1 0})^{+}$ & 2746 & - & 926 & 0.89 & 41.89 & $28 x(31)$ & $290(19), 268(24), 250(15), 227(79), 226(100), 211(7), 147(15)$ \\
\hline Hamolycarine $(7)^{*}$ & 2767 & 243 & - & 321 & - & $315(<1)$ & $200(<1,178(2), 109(100), 150(1), 10022), 94(3), 82(3)$ \\
\hline Albornaculine $(6)^{*}$ & 2815 & 7.16 & - & 66.41 & 1339 & $345(<1)$ & $221(1,193(1), 165(1), 110(10), 109(100), 108(25), 942), 82(3)$ \\
\hline Pseudalymrine $(\mathbf{1 1})^{*}$ & 2823 & - & 064 & - & 402 & $289(23)$ & $27021), 252(12,228(100,214(10), 14 \pi(17), 111(18), 82(10)$ \\
\hline 2a-Methaxyhomol yor rine $(\mathbf{8})^{+-}$ & 2870 & - & - & - & 064 & $345(<1)$ & $206(<1,178(2), 150(1), 139(100), 12464), 96(5), 94(5), 81(3)$ \\
\hline 2a,7-Dimethoxyhomolycarine $(9)^{+}$ & 2962 & - & - & 0.80 & 1.88 & $375(<1)$ & $23 \alpha(<1), 139(100), 124(54), 221(2), 193(2), 96(3), 94(3), 81(2)$ \\
\hline
\end{tabular}

NI: Retention Index.

Alkakid percentage in the total mixture of allaloids from $H$ anliam.

- Alkaloid percentage in the total mixture of alkalaids from $H$ calyporatum.

cTraces 420 of $\mathrm{TC}$.

d Tzzettine detection by GC-MS mean identification of both alkaloids tzzettine (19) and pretazettine (20) (de Andr ale et al, 201 2b)

Alkaloids identified using an in-home MS databuse.

424

- Alkakids identified using the NIST 05 datahuse; recur sive procedure, HR-MS and literature data. 
429 Table 2. ${ }^{1} \mathrm{H}$ NMR, COSY, NOESY, HSQC, and HMBC data of aulicine (1) (400 MHz, $\left.\mathrm{CDCl}_{3}\right)$.

430

\begin{tabular}{|c|c|c|c|c|c|}
\hline Position & $\delta_{\mathrm{H}}(J$ in $\mathrm{Hz})$ & $\cos Y$ & NOESY & HSQC & HMBC \\
\hline $1 \alpha(\mathrm{ax})$ & $1.77 \mathrm{td}(14.0,4.4)$ & $\mathrm{H}-1 \beta, \mathrm{H}-2 \alpha, \mathrm{H}-2 \beta$ & $\mathrm{H}-1 \beta, \mathrm{H}-2 \alpha$ & $26.8 t$ & C-2, C-10b, C-11 \\
\hline $1 \beta(\mathrm{eq})$ & $3.10-3.20 \mathrm{~m}$ & $\mathrm{H}-1 \alpha, \mathrm{H}-2 \alpha, \mathrm{H}-2 \beta$ & $\mathrm{H}-1 \alpha, \mathrm{H}-2 \beta, \mathrm{H}-11$ exo & & C-10b \\
\hline $2 \alpha(\mathrm{eq})$ & $2.04 \mathrm{~m}$ & $\mathrm{H}-1 \alpha, \mathrm{H}-1 \beta, \mathrm{H}-2 \beta, \mathrm{H}-3$ & $\mathrm{H}-1 \alpha, \mathrm{H}-2 \beta, \mathrm{H}-3,3-\mathrm{OMe}$ & $27.7 t$ & \\
\hline $2 \beta(a x)$ & 1.44 tdd $(13.5,11.5,4.0)$ & $\mathrm{H}-1 \alpha, \mathrm{H}-1 \beta, \mathrm{H}-2 \alpha, \mathrm{H}-3$ & $\mathrm{H}-1 \beta, \mathrm{H}-2 \alpha, \mathrm{H}-4 \beta, \mathrm{H}-11$ exo & & C-3 \\
\hline $3(\mathrm{ax})$ & $3.10-3.20 \mathrm{~m}$ & $\mathrm{H}-2 \alpha, \mathrm{H}-2 \beta, \mathrm{H}-4 \alpha, \mathrm{H}-4 \beta$ & $\mathrm{H}-2 \alpha, \mathrm{H}-4 \alpha, \mathrm{H}-4 \mathrm{a}$ & $77.6 d$ & 3-OMe \\
\hline $4 \alpha(\mathrm{eq})$ & 2.13 brd (12.4) & $\mathrm{H}-3, \mathrm{H}-4 \beta, \mathrm{H}-4 \mathrm{a}$ & $\mathrm{H}-3, \mathrm{H}-4 \beta, \mathrm{H}-4 \mathrm{a}, 3-\mathrm{OMe}$ & $33.8 t$ & $\mathrm{C}-10 \mathrm{~b}$ \\
\hline $4 \beta(\mathrm{ax})$ & $1.21 q(12.4)$ & $H-3, H-4 \alpha, H-4 a$ & $\mathrm{H}-2 \beta, \mathrm{H}-4 \alpha, \mathrm{H}-11$ exo, H-12exo & & $C-2, C-3, C-4 a$ \\
\hline $4 a$ & $2.93 d d(12.4,5.2)$ & $\mathrm{H}-4 \alpha, \mathrm{H}-4 \beta$ & $\mathrm{H}-3, \mathrm{H}-4 \alpha, \mathrm{H}-6 \alpha$ & $67.9 d$ & $C-4, C-6, C-10 a, C-11, C-12$ \\
\hline $6 \alpha$ & $4.38 d(16.8)$ & $\mathrm{H}-6 \beta, \mathrm{H}-7$ & $\mathrm{H}-4 \mathrm{a}, \mathrm{H}-6 \beta, \mathrm{H}-7$ & $62.7 t$ & C-6a, C-7, C-10a, C-12 \\
\hline $6 \beta$ & $3.71 d(16.8)$ & $\mathrm{H}-6 \alpha, \mathrm{H}-7$ & $\mathrm{H}-6 \alpha, \mathrm{H}-7, \mathrm{H}-12$ endo & & $C-4 a, C-6 a, C-7, C-10 a, C-12$ \\
\hline $6 a$ & & & & $130.1 s$ & \\
\hline 7 & $6.10 \mathrm{~s}$ & H- $6 \alpha, \mathrm{H}-6 \beta, 8-0 \mathrm{Me}$ & H- $6 \alpha, \mathrm{H}-6 \beta, 8-0 \mathrm{Me}$ & $101.0 d$ & $C-6, C-8, C-9, C-10 a$ \\
\hline 8 & & & & $150.2 \mathrm{~s}$ & \\
\hline 9 & & & & $133.9 s$ & \\
\hline 10 & & & & $146.8 s$ & \\
\hline $10 \mathrm{a}$ & & & & $126.0 \mathrm{~s}$ & \\
\hline $10 \mathrm{~b}$ & & & & $43.2 \mathrm{~s}$ & \\
\hline 11endo & 1.90 ddd $(12.0,8.8,3.2)$ & $\mathrm{H}-11$ exo, $\mathrm{H}-12$ endo, $\mathrm{H}-12$ exo & $\mathrm{H}-11$ exo, $\mathrm{H}-12 e n d o$ & $36.5 t$ & $C-4 a, C-10 b$ \\
\hline 11 exo & 2.23 ddd $(12.4,10.4,6.4)$ & $\mathrm{H}-11$ endo, $\mathrm{H}-12$ endo, $\mathrm{H}-12$ exo & $\mathrm{H}-1 \beta, \mathrm{H}-2 \beta, \mathrm{H}-4 \beta, \mathrm{H}-11$ endo, $\mathrm{H}-12$ exo & & C-1, C-10a, C-10b, C-12 \\
\hline 12endo & 2.78 ddd $(12.8,8.8,6.4)$ & $\mathrm{H}-11$ endo, $\mathrm{H}-11$ exo, $\mathrm{H}-12$ exo & $\mathrm{H}-6 \beta, \mathrm{H}-11$ endo, $\mathrm{H}-12$ exo & $52.2 t$ & $C-4 a, C-6, C-11$ \\
\hline 12 exo & 3.36 ddd $(12.8,10.0,3.2)$ & $\mathrm{H}-11$ endo, $\mathrm{H}-11$ exo, $\mathrm{H}-12$ endo & $\mathrm{H}-4 \beta, \mathrm{H}-11$ exo, $\mathrm{H}-12$ endo & & C-6 \\
\hline 3-OMe & $3.38 s(3 \mathrm{H})$ & & $\mathrm{H}-2 \alpha, \mathrm{H}-4 \alpha$ & $55.6 q$ & $\mathrm{C}-3$ \\
\hline 8-OMe & $3.80 s(3 \mathrm{H})$ & $\mathrm{H}-7$ & $\mathrm{H}-7$ & $55.7 q$ & C-8 \\
\hline 9-OMe & $3.87 s(3 \mathrm{H})$ & & & $61.0 q$ & C-9 \\
\hline
\end{tabular}

432

433

434 
435 Table $3{ }^{1} \mathrm{H}$ NMR, COSY, NOESY, HSQC, and HMBC data of 3-O-methyl-epimacowine (2) (500 $\left.436 \mathrm{MHz}, \mathrm{CDCl}_{3}\right)$.

\begin{tabular}{|c|c|c|c|c|c|}
\hline Position & $\delta_{\mathrm{H}}(J$ in $\mathrm{Hz})$ & $\cos Y$ & NOESY & $\mathrm{HSQC}$ & HMBC \\
\hline 1 & $6.48 d d(10.0,2.0)$ & $\mathrm{H}-2$ & $\mathrm{H}-2, \mathrm{H}-10$ & $129.1 d$ & C-3, C-4a, C-10a, C-11 \\
\hline 2 & $5.84 d t(10.0,1.5)$ & $\mathrm{H}-1$ & $\mathrm{H}-1, \mathrm{H}-3,3-\mathrm{OMe}$ & $129.2 d$ & $C-4, C-10 b$ \\
\hline 3 & $4.00 d d t(10.5,5.5,2.0)$ & $\mathrm{H}-4 \alpha, \mathrm{H}-4 \beta$ & $\mathrm{H}-2, \mathrm{H}-4 \alpha, \mathrm{H}-4 \mathrm{a}, 3-\mathrm{OMe}$ & $76.3 d$ & $\mathrm{C}-1,3-\mathrm{OMe}$ \\
\hline $4 \alpha$ & $2.29 \mathrm{~m}$ & $\mathrm{H}-3, \mathrm{H}-4 \beta, \mathrm{H}-4 \mathrm{a}$ & $\mathrm{H}-3, \mathrm{H}-4 \mathrm{a}, \mathrm{H}-4 \beta$ & $30.8 t$ & $C-2, C-3, C-4 a, C-10 b$ \\
\hline $4 \beta$ & $1.58 d d d(13.5,12.0,10.5)$ & $\mathrm{H}-3, \mathrm{H}-4 \alpha, \mathrm{H}-4 \mathrm{a}$ & $\mathrm{H}-4 \alpha, \mathrm{H}-11$ exo, H-12exo & & $C-3, C-4 a, C-10 b$ \\
\hline $4 a$ & $3.28 d d(13.5,4.0)$ & $\mathrm{H}-4 \alpha, \mathrm{H}-4 \beta$ & $\mathrm{H}-3, \mathrm{H}-4 \alpha, \mathrm{H}-6 \alpha$ & $66.8 d$ & C-12 \\
\hline $6 \alpha$ & $4.45 d(16.5)$ & $\mathrm{H}-6 \beta$ & $\mathrm{H}-4 \mathrm{a}, \mathrm{H}-6 \beta, \mathrm{H}-7$ & $61.5 t$ & C-6a, C-7, C-10a, C-12 \\
\hline $6 \beta$ & $3.82 d(17.0)$ & $H-6 \alpha$ & $\mathrm{H}-6 \alpha, \mathrm{H}-7, \mathrm{H}-12$ endo & & C-4a, C-6a, C-7, C-10a, C-12 \\
\hline $6 а$ & & & & $125.0 \mathrm{~s}$ & \\
\hline 7 & $6.59 \mathrm{~s}$ & & H- $6 \alpha, \mathrm{H}-6 \beta$ & $113.0 d$ & C-6, C-9, C-10a \\
\hline 8 & & & & $144.3 \mathrm{~s}$ & \\
\hline 9 & & & & $145.3 \mathrm{~s}$ & \\
\hline 10 & $6.78 \mathrm{~s}$ & & $\mathrm{H}-1,9-\mathrm{OMe}$ & $104.9 d$ & C-6a, C-8, C-10a, C-10b \\
\hline $10 \mathrm{a}$ & & & & $136.7 \mathrm{~s}$ & \\
\hline $10 \mathrm{~b}$ & & & & $44.7 \mathrm{~s}$ & \\
\hline 11endo & $2.20 d d d(12.0,9.0,4.5)$ & H-11exo, H-12endo, H-12exo & $\mathrm{H}-11$ exo, $\mathrm{H}-12 e n d o$ & $44.8 t$ & C-4a, C-10a, C-10b, C-12 \\
\hline 11 exo & $2.12 d d d(12.0,10.5,6.0)$ & $\mathrm{H}-11$ endo, $\mathrm{H}-12 e n d o, \mathrm{H}-12$ exo & $\mathrm{H}-4 \beta, \mathrm{H}-11$ endo, $\mathrm{H}-12$ exo & & C-1, C-10a, C-10b, C-12 \\
\hline 12endo & $2.95 d d d(13.0,9.0,6.0)$ & $\mathrm{H}-11$ endo, $\mathrm{H}-11$ exo, $\mathrm{H}-12$ exo & $\mathrm{H}-6 \beta, \mathrm{H}-11$ endo, $\mathrm{H}-12$ exo & $53.2 t$ & C-4a, C-6, C-10b \\
\hline 12 exo & $3.50 \mathrm{ddd}(13.0,10.5,4.5)$ & $\mathrm{H}-11$ endo, $\mathrm{H}-11$ exo, $\mathrm{H}-12$ endo & $\mathrm{H}-4 \beta, \mathrm{H}-12$ endo, $\mathrm{H}-11$ exo & & C-6 \\
\hline 3-OMe & $3.42 \mathrm{~s}(3 \mathrm{H})$ & & $\mathrm{H}-2, \mathrm{H}-3$ & $56.2 q$ & $\mathrm{C}-3$ \\
\hline 9-OMe & $3.89 \mathrm{~s}(3 \mathrm{H})$ & & H-10 & $56.2 q$ & C-9 \\
\hline
\end{tabular}

438

439

440

441 
442 Table $4{ }^{1} \mathrm{H}$ NMR, COSY, and HSQC data of 11-oxohaemanthamine (3) (500 MHz, $\mathrm{CDCl}_{3}$ ).

\begin{tabular}{|c|c|c|c|}
\hline Position & $\delta_{\mathrm{H}}(J$ in $\mathrm{Hz})$ & COSY & HSQC \\
\hline 1 & $6.54 d(10.0)$ & $\mathrm{H}-2$ & $126.8 d$ \\
\hline 2 & $6.21 d d d(10.0,5.5,1.5)$ & $\mathrm{H}-1, \mathrm{H}-3$ & $129.5 d$ \\
\hline 3 & $3.84 d d d(5.5,3.5,2.0)$ & $\mathrm{H}-2, \mathrm{H}-4 \alpha ; \mathrm{H}-4 \beta$ & $71.8 d$ \\
\hline $4 \alpha$ & $1.47 \operatorname{td}(14.0,4.0)$ & $\mathrm{H}-3 ; \mathrm{H}-4 \beta, \mathrm{H}-4 \mathrm{a}$ & $29.8 t$ \\
\hline $4 \beta$ & 2.25 brd $(14.0)$ & $\mathrm{H}-3 ; \mathrm{H}-4 \alpha, \mathrm{H}-4 \mathrm{a}$ & \\
\hline $4 a$ & $3.55 \mathrm{~m}$ & $\mathrm{H}-4 \alpha ; \mathrm{H}-4 \beta$ & $61.5 d$ \\
\hline $6 \alpha$ & $3.83 d(17.0)$ & $\mathrm{H}-6 \beta, \mathrm{H}-7$ & $60.6 t$ \\
\hline $6 \beta$ & $4.58 d(17.0)$ & $\mathrm{H}-6 \alpha, \mathrm{H}-7$ & \\
\hline 7 & $6.52 s$ & H- $6 \alpha, \mathrm{H}-6 \beta$ & $106.9 d$ \\
\hline 10 & $6.83 s$ & & $104.2 d$ \\
\hline 12endo & $3.27 d d(18.5,1.5)$ & $\mathrm{H}-12$ exo & $59.3 t$ \\
\hline 12 exo & $3.56 d(18.5)$ & $\mathrm{H}-12$ endo & \\
\hline 3-OMe & $3.37 s(3 \mathrm{H})$ & & $56.8 q$ \\
\hline $\mathrm{OCH}_{2} \mathrm{O}$ & $5.922 d(1.5)$ & & $101.3 t$ \\
\hline
\end{tabular}

444

445

446 
447 Table $5{ }^{1} \mathrm{H}$ NMR, COSY, NOESY, HSQC, and HMBC data of 7-methoxy-O-methyllycorenine (4) $448 \quad\left(500 \mathrm{MHz}, \mathrm{CD}_{3} \mathrm{OD}\right)$.

\begin{tabular}{|c|c|c|c|c|c|}
\hline Position & $\delta_{\mathrm{H}}(\mathrm{J}$ in $\mathrm{Hz})$ & $\cos Y$ & NOESY & $\mathrm{HSQC}$ & HMBC \\
\hline 1 & 4,40 brd $(6.5)$ & $\mathrm{H}-2 \alpha, \mathrm{H}-2 \beta, \mathrm{H}-3, \mathrm{H}-10 \mathrm{~b}$ & $\mathrm{H}-2 \alpha, \mathrm{H}-2 \beta, \mathrm{H}-10 \mathrm{~b}, 6-\mathrm{OMe}$ & $67.0 d$ & C-3, C-4a, C-6, C-10a \\
\hline $2 \alpha$ & $2,67 d d t(19.0,6.5,3.0)$ & $\mathrm{H}-1, \mathrm{H}-2 \beta, \mathrm{H}-3, \mathrm{H}-4 \mathrm{a}$ & $\mathrm{H}-1, \mathrm{H}-2 \beta, \mathrm{H}-3$ & $32.5 t$ & \\
\hline $2 \beta$ & $2,29 d t(19.5,3.0)$ & $\mathrm{H}-1, \mathrm{H}-2 \alpha, \mathrm{H}-3, \mathrm{H}-4 \mathrm{a}$ & $\mathrm{H}-1, \mathrm{H}-2 \alpha, \mathrm{H}-3$ & & \\
\hline 3 & 5,55 brs & $\mathrm{H}-1, \mathrm{H}-2 \alpha, \mathrm{H}-2 \beta, \mathrm{H}-4 \mathrm{a}, \mathrm{H}-11 \alpha / \beta$ & $\mathrm{H}-2 \alpha, \mathrm{H}-2 \beta, \mathrm{H}-11 \alpha / \beta$ & $118.1 d$ & \\
\hline 4 & & & & $140.2 s$ & \\
\hline $4 a$ & 2,92 br d (10.0) & $\mathrm{H}-2 \alpha, \mathrm{H}-2 \beta, \mathrm{H}-3, \mathrm{H}-10 \mathrm{~b}$ & NMe & $69.2 d$ & \\
\hline $6 \beta$ & $5,52 \mathrm{~s}$ & & 6-OMe & $97.8 d$ & C-1, C-7, C-6a, C-10a, 6-OMe \\
\hline $6 \mathbf{a}$ & & & & $121.7 \mathrm{~s}$ & \\
\hline 7 & & & & $153.2 \mathrm{~s}$ & \\
\hline 8 & & & & $142.9 s$ & \\
\hline 9 & & & & $154.7 \mathrm{~s}$ & \\
\hline 10 & $6.85 \mathrm{~s}$ & 9-OMe & H-10b, 9-OMe, NMe & $110.0 d$ & C-6a, C-8, C-9, C-10a, C-10b, C-7 \\
\hline 10a & & & & $134.1 s$ & \\
\hline 10b & $2.47 d d(10.0,2.0)$ & $\mathrm{H}-1, \mathrm{H}-4 \mathrm{a}$ & $\mathrm{H}-1, \mathrm{H}-10, \mathrm{H}-12 \alpha$ & $44.1 d$ & C-4a, C-6a, C-10, C-10a \\
\hline $11 \alpha \mid \beta$ & $2.49-2.58 \mathrm{~m}$ & $\mathrm{H}-3, \mathrm{H}-12 \alpha, \mathrm{H}-12 \beta$ & $\mathrm{H}-3, \mathrm{H}-12 \alpha$ & $28.6 t$ & \\
\hline $12 \alpha$ & $3.22 d d d(10.5,7.5,3.0)$ & $\mathrm{H}-11 \alpha / \beta, \mathrm{H}-12 \beta$ & $\mathrm{H}-10 \mathrm{~b}, \mathrm{H}-11 \alpha / \beta, \mathrm{H}-12 \beta, \mathrm{NMe}$ & $57.7 t$ & \\
\hline $12 \beta$ & $2.42 \mathrm{~m}$ & $\mathrm{H}-11 \alpha / \beta, \mathrm{H}-12 \alpha$ & $\mathrm{H}-12 \alpha, \mathrm{NMe}$ & & \\
\hline 6-OMe & $3.51 \mathrm{~s}(3 \mathrm{H})$ & & $\mathrm{H}-1, \mathrm{H}-6 \beta$ & $55.6 q$ & C-6 \\
\hline 7-OMe & $3.89 \mathrm{~s}(3 \mathrm{H})$ & & & $61.5 q$ & C-7 \\
\hline 8-OMe & $3.82 \mathrm{~s}(3 \mathrm{H})$ & & & $61.2 q$ & C-8 \\
\hline 9-OMe & $3.87 \mathrm{~s}(3 \mathrm{H})$ & $\mathrm{H}-10$ & $\mathrm{H}-10$ & $56.6 q$ & C-9 \\
\hline NMe & $2.11 \mathrm{~s}(3 \mathrm{H})$ & & $\mathrm{H}-4 \mathrm{a}, \mathrm{H}-10, \mathrm{H}-12 \alpha, \mathrm{H}-12 \beta$ & $44.0 q$ & C- $4 a, C-12$ \\
\hline
\end{tabular}


452 Table $6{ }^{1} \mathrm{H}$ NMR, COSY, NOESY, HSQC, and HMBC data of nerinine (5) (400 MHz, CDCl ${ }^{3}$ ).

453

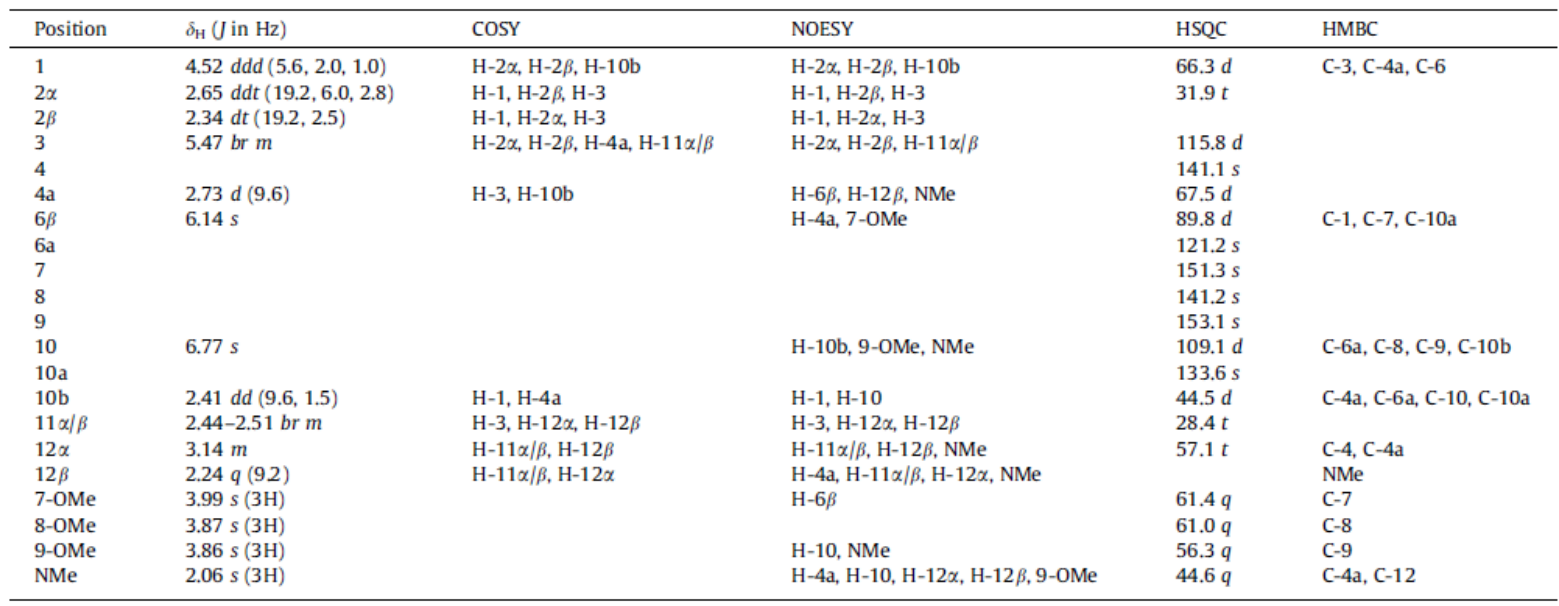

455

456

457

458 
459 Table $7{ }^{1} \mathrm{H}$ NMR, COSY, NOESY, HSQC, and HMBC data of albomaculine (6) (400 MHz, $\left.\mathrm{CDCl}_{3}\right)$. 460

\begin{tabular}{|c|c|c|c|c|c|}
\hline Position & $\mathrm{d}_{\mathrm{b}}(\mathrm{J}$ in $\mathrm{Hz})$ & $\cos Y$ & NOESY & $H S Q C$ & HMBC \\
\hline 1 & $468 \mathrm{br} \mathrm{m}$ & $\mathrm{H}-22 \mathrm{z} / \mathrm{\beta}, \mathrm{H}-3, \mathrm{H}-10 \mathrm{~b}$ & $\mathrm{H}-2 \mathrm{z} i \mathrm{\beta}, \mathrm{H}-10 \mathrm{~b}$ & $763 d$ & $\mathrm{C}-3, \mathrm{C}-42 \mathrm{C}-1 \mathrm{a}$ \\
\hline $2 a / \beta$ & $255-2.60 \mathrm{brm}$ & $\mathrm{H}-1, \mathrm{H}-3, \mathrm{H}-11 \alpha / \beta$ & $\mathrm{H}-1, \mathrm{H}=3$ & $31.0 t$ & $\mathrm{C}-1, \mathrm{C}-3, \mathrm{C}-10 \mathrm{~b}$ \\
\hline 3 & $5.48 \mathrm{brm}$ & $\mathrm{H}-1, \mathrm{H}-2 \mathrm{x}[\mathrm{\beta}, \mathrm{H}-42, \mathrm{H}-11$ aj $\beta$ & $H-2 x$ 级, $H-11 \alpha[\beta$ & $115.6 d$ & \\
\hline 42 & $272 d(100)$ & $H-3, H-10 b$ & NMe & $660 d$ & \\
\hline 6 & & & & $162.4 s$ & \\
\hline 62 & & & & $111.6 \mathrm{~s}$ & \\
\hline 7 & & & & 156.35 & \\
\hline 10 & $678 \mathrm{~s}$ & & $\mathrm{H}-10 \mathrm{~b}, 9-0 \mathrm{Me}, \mathrm{NMe}$ & $107.4 d$ & $\mathrm{C}-6 \mathrm{~s}, \mathrm{C}, 8, \mathrm{C}-10 \mathrm{~b}$ \\
\hline $10 \mathrm{a}$ & & & & $140.8 s$ & \\
\hline $10 \mathrm{~b}$ & $263 d(100)$ & $\mathrm{H}-1, \mathrm{H}-4 \mathrm{2}$ & $\mathrm{H}-1, \mathrm{H}-10$ & $455 d$ & \\
\hline $11 \alpha / \beta$ & $245-2.53 \mathrm{brm}$ & $H-2 x / \beta, H-3, H-12 x, H-12 \beta$ & $H-3, H-12 \alpha, H-12 \beta$ & $281 t$ & $c-4$ \\
\hline $12 x$ & $3.13 \mathrm{ddd}(96,7.2,36)$ & $\mathrm{H}-11 \alpha / \beta, H-12 \beta$ & $\mathrm{H}-11 \alpha j \beta, \mathrm{H}-12 \beta, \mathrm{NMe}$ & $566 \mathrm{t}$ & \\
\hline $12 \beta$ & $223 q(96)$ & $H-11 \alpha i 8, H-12 z$ & $\mathrm{H}-11$ ajß. $\mathrm{H}-12 \mathrm{z}$ & & $\mathrm{C}-11, \mathrm{NMe}$ \\
\hline 7-OMe & $399=(3 \mathrm{H})$ & & & $621 \mathrm{t}$ & C-7 \\
\hline 8-OMe & $389=(3 \mathrm{H})$ & & & $613 t$ & C-8 \\
\hline
\end{tabular}

462

463 
465

466
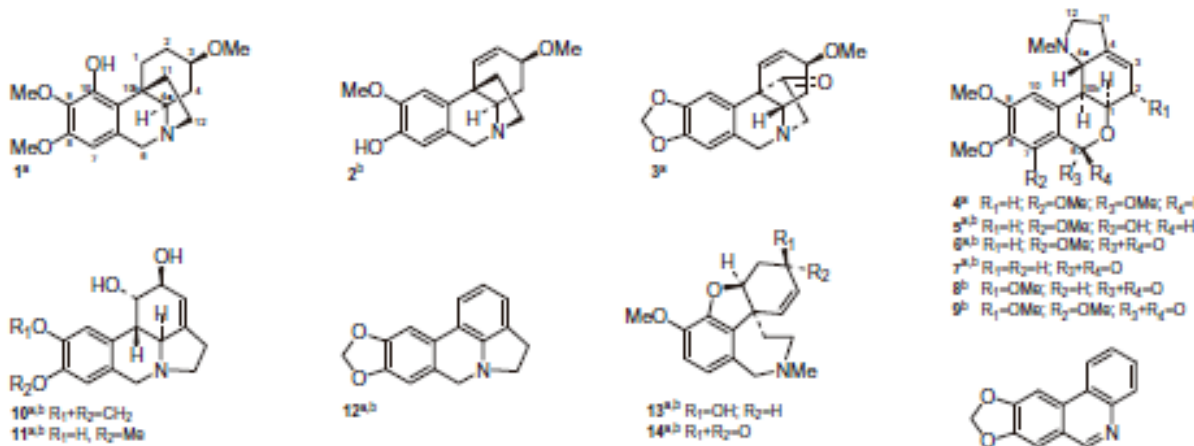

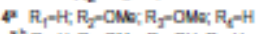

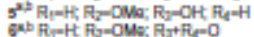

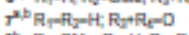

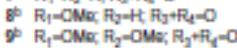
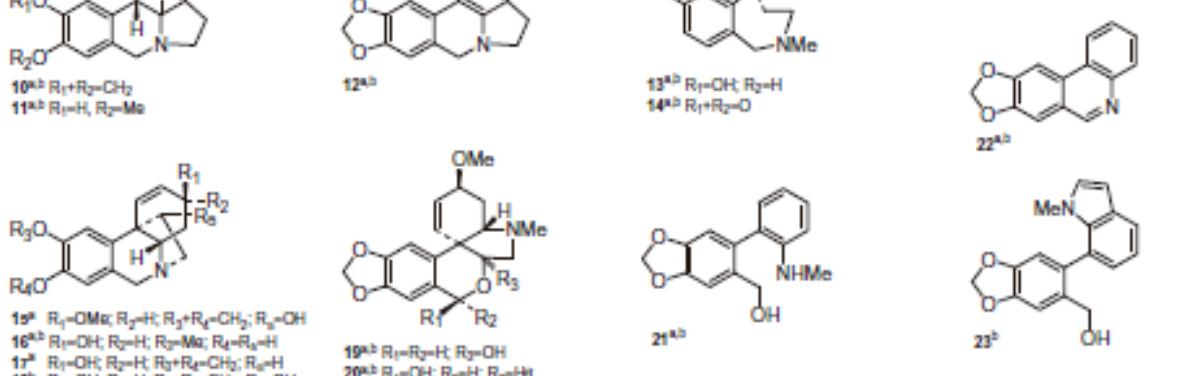

467

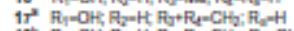

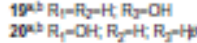

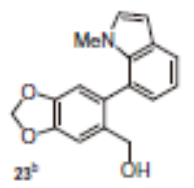

468

469

470 
471

472

473
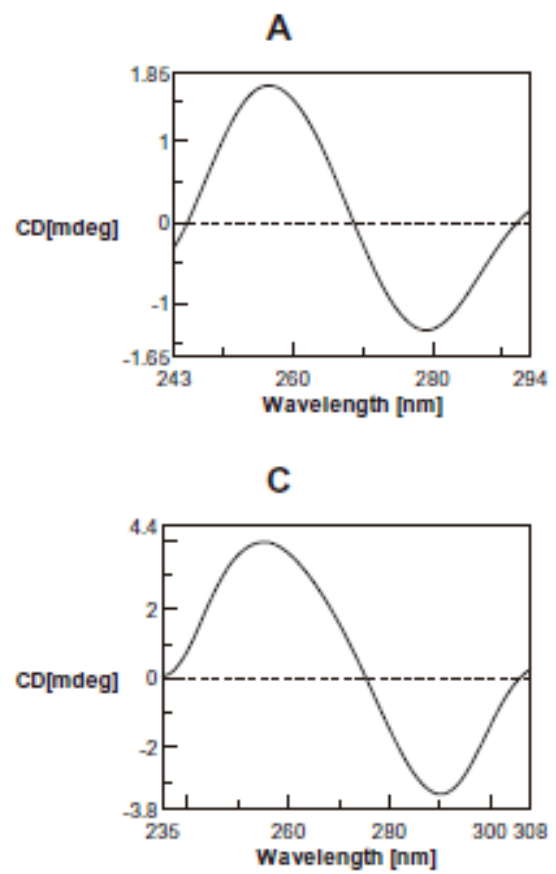

Figure 2

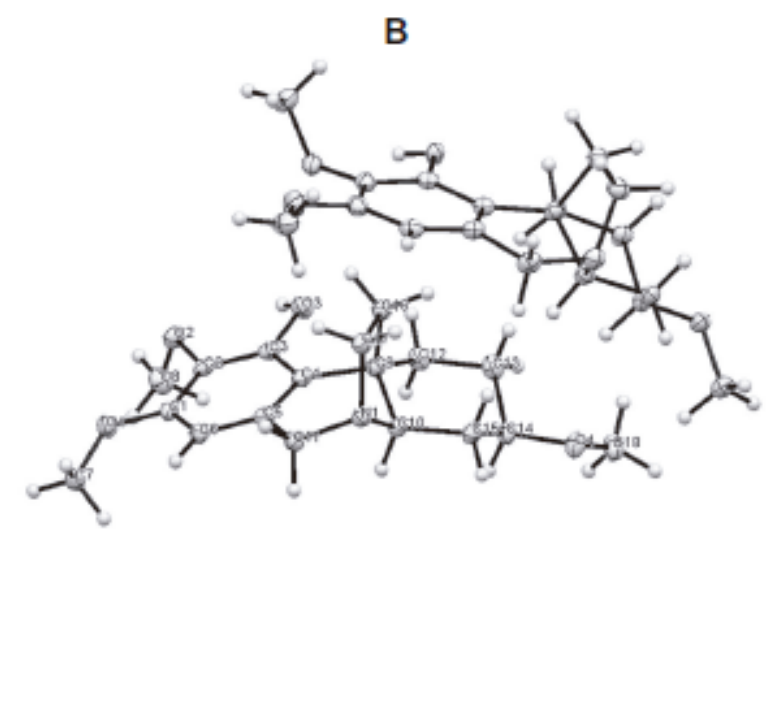

